\title{
Alcohol Binge Drinking during Adolescence or Dependence during Adulthood Reduces Prefrontal Myelin in Male Rats
}

\author{
Wanette M. Vargas, ${ }^{1,2}$ Lynn Bengston, ${ }^{2}{ }^{\oplus N}$ Nicholas W. Gilpin, ${ }^{3}{ }^{\circledR B}$ Brian W. Whitcomb, ${ }^{4}$ and ${ }^{\circ}$ Heather N. Richardson ${ }^{2}$ \\ ${ }^{1}$ Neuroscience and Behavior Program and ${ }^{2}$ Department of Psychological and Brain Sciences, University of Massachusetts, Amherst, Massachusetts 01003 , \\ ${ }^{3}$ Department of Physiology, Louisiana State University Health Sciences Center, New Orleans, Louisiana 70112, and ${ }^{4}$ Department of Public Health, \\ University of Massachusetts, Amherst, Massachusetts 01003
}

Teen binge drinking is associated with low frontal white matter integrity and increased risk of alcoholism in adulthood. This neuropathology may result from alcohol exposure or reflect a pre-existing condition in people prone to addiction. Here we used rodent models with documented clinical relevance to adolescent binge drinking and alcoholism in humans to test whether alcohol damages myelinated axons of the prefrontal cortex. In Experiment 1, outbred male Wistar rats self-administered sweetened alcohol or sweetened water intermittently for 2 weeks during early adolescence. In adulthood, drinking behavior was tested under nondependent conditions or after dependence induced by 1 month of alcohol vapor intoxication/withdrawal cycles, and prefrontal myelin was examined 1 month into abstinence. Adolescent binge drinking or adult dependence induction reduced the size of the anterior branches of the corpus callosum, i.e., forceps minor $\left(\mathrm{CC}_{\mathrm{FM}}\right)$, and this neuropathology correlated with higher relapse-like drinking in adulthood. Degraded myelin basic protein in the gray matter medial to the $\mathrm{CC}_{\mathrm{FM}}$ of binge rats indicated myelin was damaged on axons in the $\mathrm{mPFC}$. In follow-up studies we found that binge drinking reduced myelin density in the mPFC in adolescent rats (Experiment 2 ) and heavier drinking predicted worse performance on the T-maze working memory task in adulthood (Experiment 3). These findings establish a causal role of voluntary alcohol on myelin and give insight into specific prefrontal axons that are both sensitive to alcohol and could contribute to the behavioral and cognitive impairments associated with early onset drinking and alcoholism.

Key words: adolescent; alcohol; binge; dependence; myelin; prefrontal

\section{Introduction}

Adolescence is a period of heightened vulnerability when teenagers engage in high-risk activities like binge drinking (Romer, 2010 ) as the frontal lobes undergo developmental processes including axonal myelination (Barnea-Goraly, 2005). Myelination increases conductance speed in axons and enhances information processing and cognitive performance (Blakemore and Choudhury, 2006). If prefrontal fiber tracts are sensitive to alcohol exposure during this time of plasticity, drinking could significantly impair the social and mental health trajectories of teenagers because the prefrontal cortices are responsible for evaluating reward (Taren et al., 2011) and regulating risk-taking behavior (Crone et al., 2008).

Early onset of alcohol use predicts increased impulsivity (Stephens and Duka, 2008), cognitive performance impairments

\footnotetext{
Received July 26, 2013; revised Sept. 2, 2014; accepted Sept. 23, 2014.

Author contributions: N.W.G. and H.N.R. designed research; W.M.V. and L.B. performed research; W.M.V. and B.W.W. analyzed data; W.M.V. and H.N.R. wrote the paper.

This work was funded by National Institutes of Health (NIH) Grant AA021013 (H.N.R.) and NIH PREP GrantR25GM086264 (W.M.V.). We kindly thank Chrisanthi Karanikas, Craig Mehrmann, Katherine Hemingway, Kyle O'Donnell, Maury Cole, Michael Riad, and Kristie Fierro for assistance with the experiments and Dr. David Moorman, Dr. Luke Remage-Healey, Jesse McClure, and Yi-Ling Lu for their critical reading of this manuscript.

The authors declare no competing financial interests.

Correspondence should be addressed to Heather N. Richardson, University of Massachusetts Amherst, Tobin Hall, 135 Hicks Way Amherst, MA 01003. E-mail: hrichardson@cns.umass.edu.

DOI:10.1523/JNEUROSCI.3189-13.2014

Copyright $\odot 2014$ the authors $\quad 0270-6474 / 14 / 3414777-06 \$ 15.00 / 0$
}

(Konrad et al., 2012), and alcoholism in adulthood (Grant and Dawson, 1998). Heavy episodic (binge) drinking is related to lower white matter integrity in the corpus callosum (CC) of teenagers (McQueeny et al., 2009) and in alcoholic adults (Pfefferbaum et al., 2006). The link between reduced white matter and increased addiction vulnerability in humans suggests alcohol exposure may damage myelin. Alternatively, predisposing factors could explain the relationship between adolescent drinking and frontal white matter.

The present study tested the hypothesis that alcohol damages CC myelin tracts within the PFC. Preclinical models of adolescent binge drinking (Gilpin et al., 2012) and adult dependence (Becker, 2013; Vendruscolo and Roberts, 2014) were used to elicit different in vivo alcohol exposures in outbred rats. Myelin was labeled 1 month into abstinence in adulthood to quantify white matter changes in the frontal lobes. We show that voluntary binge drinking reduces myelin density in the mPFC in adolescent rats, relates to working memory deficits in adulthood, and produces enduring prefrontal white matter loss comparable to that observed after alcohol dependence. Moreover, greater severity of prefrontal white matter neuropathology was correlated with higher levels of relapse-like drinking in adulthood. These findings give insight into myelinated prefrontal axons that are vulnerable to alcohol and may underlie adverse mental health outcomes associated with early alcohol use in humans. 
a
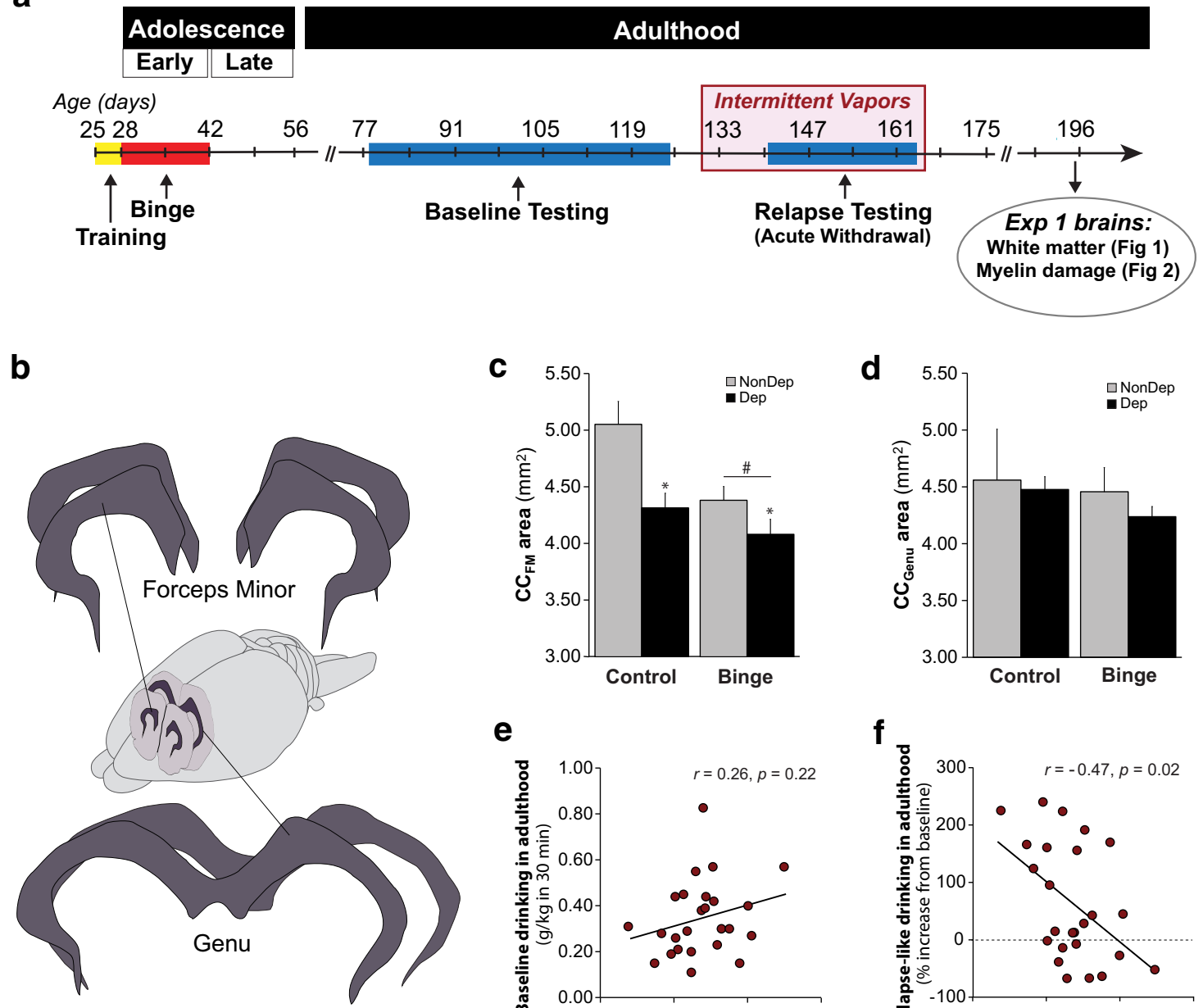
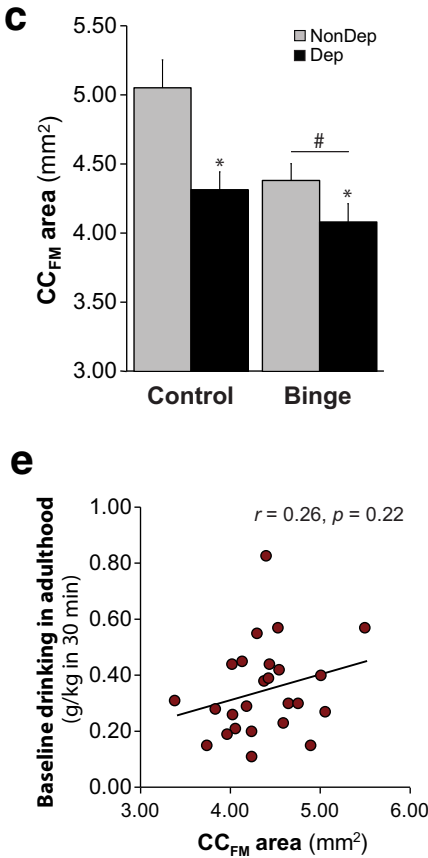
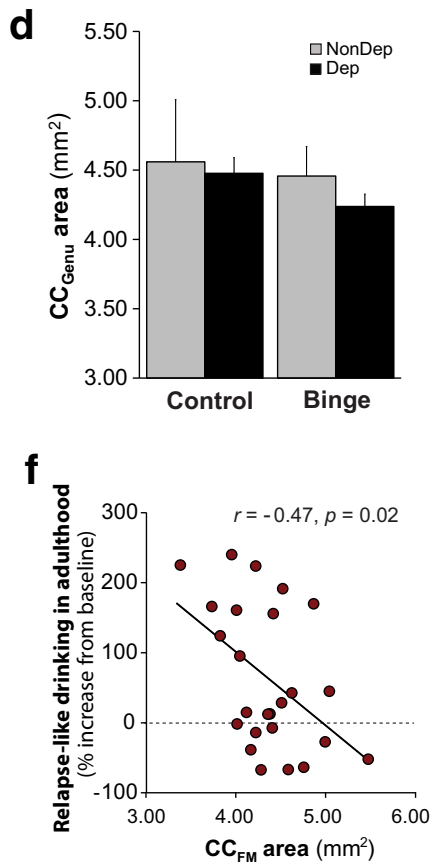

Figure 1. Alcohol causes reductions in prefrontal white matter that predict higher levels of relapse-like drinking in adulthood (Experiment 1). $\boldsymbol{a}$, Schematic illustrating the alcohol exposure time line during adolescence and adulthood. Male rats underwent voluntary, binge self-administration sessions with sweetened alcohol (binge) or sweetened water (control) during early adolescence. In adulthood, rats were tested for baseline alcohol drinking, then exposed to chronic alcohol vapors (dependent) or ambient air (nondependent), and tested for relapse drinking (details in Gilpin et

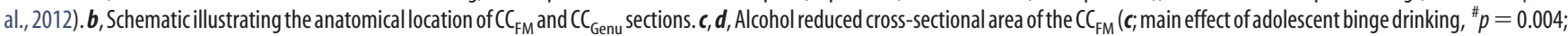
main effect of adult alcohol dependence, $\left.{ }^{*} p=0.006\right)$, but not the $\mathrm{CC}_{\mathrm{Genu}}(\boldsymbol{d}$; all $p s>0.05) . \boldsymbol{e}, \boldsymbol{f}, \mathrm{CC}_{\mathrm{FM}}$ cross-sectional area did not predict baseline alcohol intake $(\boldsymbol{e})$, but did predict the percentage increase from baseline levels after short abstinence periods, i.e., relapse-like drinking ( $\boldsymbol{f} ; p=0.02$ ). Data expressed as mean \pm SEM ( $n=4-9$ rats/group).

\section{Materials and Methods}

Animals

Male Wistar rats were shipped with their mothers on postnatal day $(\mathrm{P}) 18$ from Charles River, weaned, and housed in triads beginning on P21. All procedures were performed according to the National Institutes of Health Guide for the Care and Use of Laboratory Animals and approved by the Institutional Animal Care and Use Committee.

\section{Study design}

Experiment 1: effect of binge drinking and dependence on prefrontal white matter. The experimental design is shown in Figure $1 a$. Rats $(N=27)$ were given differential exposure to alcohol during adolescence and adulthood (described briefly below; details in Gilpin et al., 2012). After operant training, $\mathrm{P} 28$ rats were randomly assigned to $\operatorname{control}(n=9)$ or binge $(n=18)$ treatment [see below, Adolescent alcohol exposure (experiments 1-3)]. A priori, a larger binge group was planned to account for anticipated variability in alcohol self-administration. After 5 weeks of abstinence (beginning on P78), binge and control rats were tested for baseline drinking in adulthood. At P130, groups were further divided after balancing for adolescent and adult drinking behaviors, and animals were either made dependent [ 1 month of intermittent alcohol vapors; target blood alcohol levels (BALs) were $0.15-00.20 \mathrm{~g} / \mathrm{dl}$ ] or remained nondependent ( 1 month of ambient air control) and tested for relapselike drinking, i.e., augmented drinking after short deprivation periods. Details on tail nick blood collection and Analox measurement of BALs are described in Gilpin et al. (2012). Brains available for this myelin study were from (1) control nondependent $(n=4),(2)$ control dependent $(n=5)$, (3) binge nondependent $(n=9)$, and (4) binge dependent $(n=$ 9) rats that were perfused 1 month after vapor/air treatment ended. Brains were processed for quantification of prefrontal white matter loss and myelin damage, as described below.

Experiment 2: effect of binge drinking on myelinated axons in the $\mathrm{MPFC}$ of adolescent rats. The experimental design is shown in Figure 3a. Rats $(N=25)$ underwent binge $(n=8)$ or control $(n=8)$ drinking from $\mathrm{P} 28-\mathrm{P} 42$, or remained naive to operant training and alcohol $(n=9)$. The day after the binge period ended, animals were perfused and brain tissue was processed and analyzed for myelin density (described below). Brain sections from a small proportion of these animals were used in a previous study (Karanikas et al., 2013).

Experiment 3: effect of binge drinking on working memory (T-maze). The experimental design is shown in Figure $3 a$. Animals $(N=27)$ underwent adolescent binge $(n=13)$ or control $(n=14)$ drinking from P28-P42. After the binge period, animals were tested on P43, P44, and P48 for performance on the T-maze spontaneous alternation task as described 
a

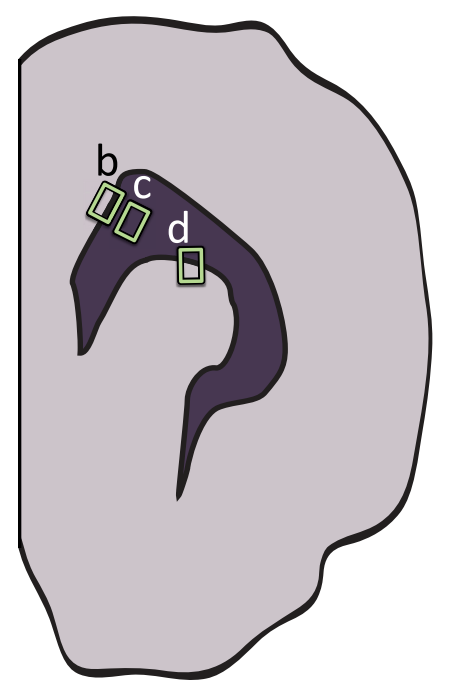

b
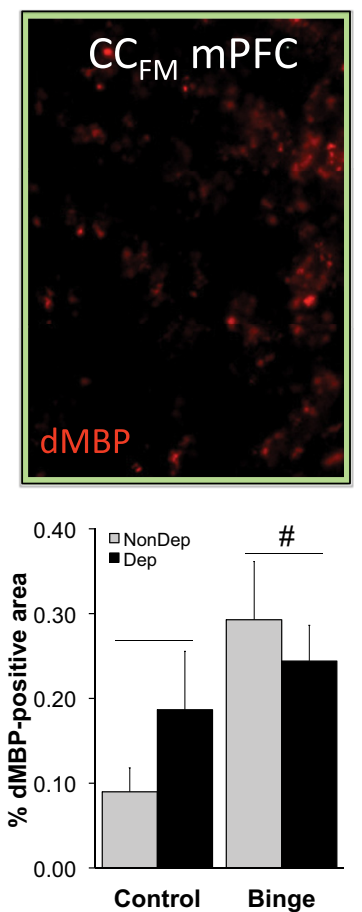

C
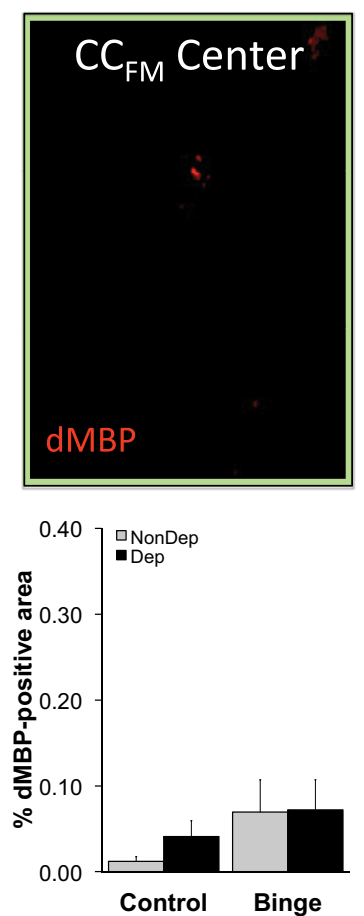

d
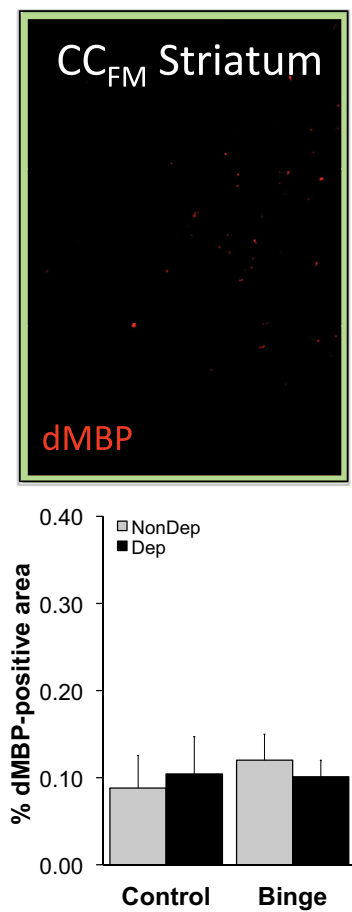

Figure 2. Adolescent alcohol causes enduring damage to $\mathrm{MPFC}$ myelin (Experiment 1). $\boldsymbol{a}$, Schematic illustrating the anatomical regions analyzed. $\boldsymbol{b}$ - $\boldsymbol{d}$, Adolescent alcohol increased myelin damage, indexed by $\mathrm{dMBP}$, in the gray matter just medial to the $\mathrm{CC}_{\mathrm{FM}}\left(\mathrm{CC}_{\mathrm{FM}} \mathrm{mPFC}\right.$; main effect of adolescent binge drinking, $\left.\# p=0.02\right)$. Adult dependence did not significantly increase dMBP in the $\mathrm{CC}_{\mathrm{FM}} \mathrm{mPFC}(\boldsymbol{b} ; p>0.05)$ and neither treatment significantly increased dMBP in the center of the medial branch of the $\mathrm{CC}_{\mathrm{FM}}\left(\mathrm{CC}_{\mathrm{FM}}(\mathrm{enter} ; \boldsymbol{c}, p>0.05)\right.$ or striatum $\left(\mathrm{CC}_{\mathrm{FM}} \mathrm{Striatum} ; \boldsymbol{d}, p>0.05\right)$. Data expressed as mean $\pm \operatorname{SEM}(n=4-9$ rats/group).

below, and were tested again in adulthood after $\sim 6$ weeks of abstinence (P88-P89).

\section{Adolescent alcohol exposure (experiments 1-3)}

Beginning on $\sim \mathrm{P} 25$, animals were trained to self-administer sweetened water ( $3 \%$ glucose $/ 0.125 \%$ saccharin/tap water). On P28, rats were either switched to sweetened alcohol $(8-10 \% \mathrm{w} / \mathrm{v}$ ethanol $/ 3 \%$ glucose $/ 0.125 \%$ saccharin/tap water; binge) or remained on sweetened water (control). Overnight operant sessions consisted of six 30 min bouts divided by time-out periods when the levers were retracted and alcohol was unavailable. Time-out periods lasted $90 \mathrm{~min}$ in Experiment 1 (Gilpin et al., 2012) and were reduced to $60 \mathrm{~min}$ in Experiments 2 and 3 to maximize operant box usage in our laboratory. Food and water were available ad libitum in the operant boxes throughout the binge exposure period.

\section{Perfusions and brain sectioning (experiments 1-2)}

Animals were intracardially perfused the day after the 2 week binge period ended (P43, Experiment 2) or several months later after drinking behavior was tested in adulthood (P196, Experiment 1, Gilpin et al., 2012). After $4 \mathrm{~h}$ post fixation and $24-48 \mathrm{~h}$ in $20 \%$ sucrose, brains were snap frozen using isopentane (2-methylbutane; Sigma) and dry ice, and stored at $-80^{\circ} \mathrm{C}$ until sectioning. Thirty-five micrometer coronal sections were sliced on a freezing microtome and stored at $-20^{\circ} \mathrm{C}$ in cryoprotectant (50\% $0.1 \mathrm{~m} \mathrm{PBS,} \mathrm{30 \%} \mathrm{ethylene} \mathrm{glycol,} \mathrm{and} \mathrm{20 \%} \mathrm{glycerol).}$

\section{Myelin labeling and microscopic analysis of prefrontal white} matter (experiment 1)

Black Gold II (BG-II) was used to impregnate myelin and label white matter in every eighth brain section (Schmued et al., 2008). For white matter microscopic analysis, brain sections were classified as (1) forceps minor $\left(\mathrm{CC}_{\mathrm{FM}}\right)$, anterior to the $\mathrm{CC}$ joining across hemispheres, $2.10-1.85$ $\mathrm{mm}$ from bregma or (2) genu $\left(\mathrm{CC}_{\mathrm{Genu}}\right)$, posterior to the joining of the left and right CC, $1.60-1.35 \mathrm{~mm}$ from bregma (Paxinos and Watson, 1998; Fig. 1b). Fifteen to 20 photomicrographs were taken using a Leica microscope $(5 \times$ objective $)$ attached to a DP71 Olympus camera and were digitally montaged for a single hemisphere. Two to four hemispheres were used for microscopic analysis of each anatomical classification for each animal. $\mathrm{CC}_{\mathrm{FM}}$ and $\mathrm{CC}_{\mathrm{Genu}}$ cross-sectional areas were quantified using ImageJ software (Rasband, 1997).

\section{Degraded myelin basic protein labeling and microscopic analysis (experiment 1)}

Using a marker of degraded myelin basic protein (dMBP), we quantified myelin damage in the center and the borders of the $\mathrm{CC}_{\mathrm{FM}}$ where these axons extend into the mPFC or the striatum (Fig. 2a). Free-floating sections were prepared using the immunohistochemistry standard protocol for dMBP (Millipore) primary antibody (1:1000), as described previously (Matsuo et al., 1997; Li and Stys, 2000), and Cy3 fluorescent secondary antibody (1:300, Jackson ImmunoResearch). Photomicrographs were taken $2.2 \mathrm{~mm}$ from bregma (20× objective) using constant imaging parameters, and were analyzed for intensity quantification using ImageJ software; the threshold function was used to highlight dMBPpositive regions. Percentage of dMBP-positive area within the total area was calculated.

\section{Myelin labeling and microscopic analysis of myelin density in the} mPFC (experiment 2)

Every 10th section was labeled for BG-II (Schmued et al., 2008), and dorsal mPFC photomicrographs were taken $2.2 \mathrm{~mm}$ from bregma $(5 \times$ objective). Aperio ImageScope software was used to quantify myelinated fiber density in cortical layers II-V by thresholding the images. Percentage of myelinated fiber area within the total area was calculated.

\section{T-maze spontaneous alternation task (experiment 3 )}

T-maze assays were conducted as previously described (Deacon and Rawlins, 2006), with the modification of a $70 \mathrm{~s}$ delay between trials, making this task mPFC dependent (Delatour and Gisquet-Verrier, 1996; Lalonde, 2002). In total, animals underwent 10 trials during adolescence and 6 trials during adulthood. 
Statistical analysis

Overall effects of adolescent alcohol exposure and adult dependence on white matter crosssectional area and $\mathrm{AMBP}$ intensity were analyzed using between-subjects two-way ANOVAs. One-way ANOVAs were used to analyze the effect of adolescent alcohol exposure on $\mathrm{mPFC}$ myelinated fiber density and on T-maze performance. Pearson correlation analyses were used to assess relationships between white matter and adolescent alcohol intake and adult baseline and relapse-like drinking behaviors, and to examine the relationship between adolescent alcohol intake and T-maze performance. Statistical significance was defined as $\leq 0.05$ using two-tailed tests. Statistical analyses were performed using R statistical software package (RCoreTeam, 2013).

\section{Results}

Binge drinking during adolescence and/or dependence during adulthood reduced frontal white matter. This reduction persisted well into abstinence (over 5 months after adolescent binge ended and 1 month after vapor exposure ended). Binge rats had smaller $\mathrm{CC}_{\mathrm{FM}}$ areas than control rats (adolescent treatment main effect, $F_{(1,21)}=$ 10.50, $p=0.004$; Fig. 1c). Likewise, alcohol-dependent rats had smaller $\mathrm{CC}_{\mathrm{FM}}$ areas than nondependent rats (adult treatment main effect, $F_{(1,21)}=9.47, p=$ 0.006, Fig. 1c). No significant interaction between adolescent and adult treatments was detected $(p=0.15)$. The $\mathrm{CC}_{\mathrm{Genu}}$, which is located just posterior to the mPFC, was not significantly altered after a history of adolescent binge drinking and adult dependence, and there was no interaction between these treatments (all $p s>$ 0.05; Fig. 1d). However, $\mathrm{CC}_{\mathrm{Genu}}$ size was significantly inversely related to adolescent alcohol consumption $(r=-0.64$, $p=0.005$; data not shown), suggesting that higher alcohol levels may be necessary to reduce $\mathrm{CC}_{\mathrm{Genu}}$ size.

We next examined behavioral correlates of white matter loss. $\mathrm{CC}_{\mathrm{FM}}$ size was not significantly correlated with baseline drinking levels $(\mathrm{g} / \mathrm{kg} / 30 \mathrm{~min}, r=0.26, p=$ 0.21; Fig. 1e). Conversely, smaller $\mathrm{CC}_{\mathrm{FM}}$ size predicted higher drinking after short deprivation periods, indexed by percentage increase in intake relative to baseline $(r=-0.47, p=0.02$; Fig. $1 f)$. No significant correlations were detected between $\mathrm{CC}_{\mathrm{Genu}}$ size and any adult drinking behaviors.

A marker of $\mathrm{dMBP}$ was next used to index myelin health and identify the axonal population of the $\mathrm{CC}_{\mathrm{FM}}$ axons damaged by alcohol. We detected significantly elevated dMBP at the dorsomedial border of the $\mathrm{CC}_{\mathrm{FM}}\left(\mathrm{CC}_{\mathrm{FM}} \mathrm{mPFC}\right)$ in rats with a history of adolescent binge drinking (adolescent treatment main effect, $F_{(1,23)}=7.00, p=0.01$; Fig. $\left.2 b\right)$. Dependence did not significantly increase $\mathrm{dMBP}$ in the $\mathrm{CC}_{\mathrm{FM}} \mathrm{mPFC}(p>0.05$; Fig. $2 b)$.

a

C

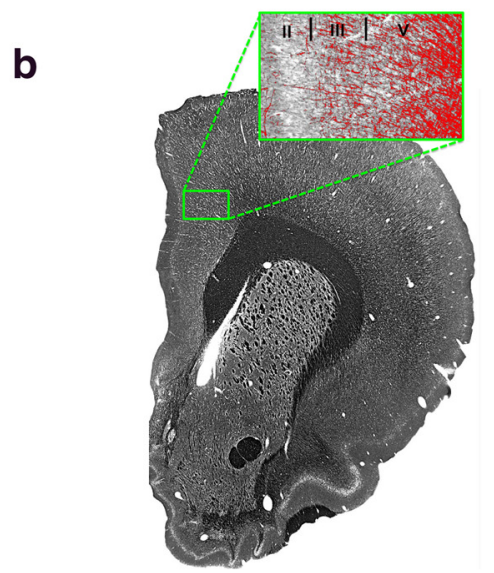

Adulthood

Adolescence Early Late

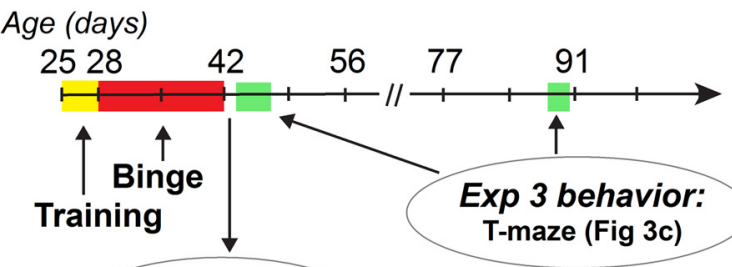

Exp 2 brains: mPFC myelinated fiber density (Fig 3b)
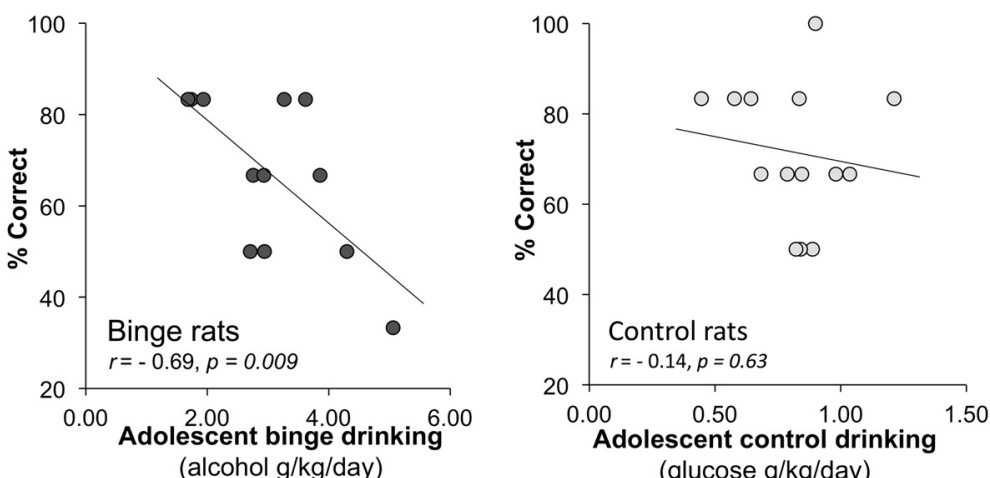

Figure 3. Adolescent alcohol decreases myelinated fiber density in the $\mathrm{MPFC}$ and predicts poor T-maze performance in adulthood (Experiments 2 and 3). $\boldsymbol{a}$, Schematic illustrating the time line of alcohol exposure during adolescence and neural and behavioral measures. Male rats underwent voluntary, binge self-administration sessions with sweetened alcohol (binge) or sweetened water (control) during early adolescence. Rats were tested on the T-maze as adolescents and again in adulthood after 6 weeks of abstinence. $\boldsymbol{b}$, Schematic illustrating the anatomical location of the myelinated fiber density measurement (left). Alcohol reduced myelinated fiber density in the $\mathrm{mPFC}\left({ }^{*} p=0.002\right)$. $c$, There was a significant negative correlation between daily adolescent consumption and percentage correct responses in the T-maze in adulthood in binge rats (left graph; $p=0.009$ ). This relationship was not observed in control rats (right graph; $p>0.05$ ) and no relationships were detected between drinking behavior and T-maze performance tested in adolescence ( $p s>0.05$; data not shown). Data expressed as mean $\pm \operatorname{SEM}(\boldsymbol{b}, n=$ $8-9$ rats/group; $c, n=13-14$ rats/group).

dMBP was detected in the $\mathrm{CC}_{\mathrm{FM}}$ Center and $\mathrm{CC}_{\mathrm{FM}}$ Striatum, but the intensity did not significantly differ between groups ( $p$ s > 0.05; Fig. 2c,d).

Based on the findings above, we next tested the hypothesis that binge drinking decreases myelinated axons in layers II-V of the mPFC of adolescent rats. Indeed, the day after the last binge session, mPFC myelinated axonal density was reduced in binge 
Table 1. Summary of adolescent alcohol binge drinking for experiments 1-3

\begin{tabular}{llll}
\hline Groups & $\begin{array}{l}\text { Experiment 1 } \\
\text { Mean } \pm \text { SEM }\end{array}$ & $\begin{array}{l}\text { Experiment 2 } \\
\text { Mean } \pm \text { SEM }\end{array}$ & $\begin{array}{l}\text { Experiment 3 } \\
\text { Mean } \pm \text { SEM }\end{array}$ \\
\hline Binge & $3.21 \pm 0.38$ & $2.96 \pm 0.31$ \\
Binge nondependent & $4.36 \pm 0.16$ & & \\
Binge dependent & $4.52 \pm 0.15$ & & \\
\hline
\end{tabular}

Alcohol binge consumption during adolescence $(\mathrm{g} / \mathrm{kg} / \mathrm{d})$ for the groups in each experiment. Data shown as mean \pm SEM.

drinking rats compared with control and naive rats $\left(F_{(2,21)}=\right.$ 8.43; $p=0.002$; Fig. $3 b$ ).

We next explored whether binge drinking related to performance on the mPFC-dependent, spontaneous alternation T-maze working memory task. There was no main effect of binge drinking on performance $(p>0.05)$, but the amount of alcohol consumed early in adolescence predicted poor performance on the T-maze in adulthood ( $r=-0.69, p=0.009$; Fig. $3 c$ ). Conversely, this relationship between sweetened water drinking and T-maze performance was not observed in control rats $(r=$ $-0.14, p=0.63$; Fig. $3 c$ ). There were no significant relationships between adolescent drinking and T-maze performance at the end of the adolescent treatment period for either group ( $p s>0.05$; data not shown).

Table 1 summarizes average daily alcohol intake over the 2 week adolescent binge period for rats in Experiments 1-3. BALs ranged between 0.0 and $0.17 \mathrm{~g} / \mathrm{dl}$ after $0.0-2.20 \mathrm{~g} / \mathrm{kg}$ alcohol consumption in single, 30 min self-administration bouts, which were randomly assessed from animals in the three experiments. These BALs are moderate and similar to what has been reported for adolescent rats consuming sweetened alcohol in the home cage (Walker et al., 2008; Gilpin et al., 2012; Broadwater et al., 2013).

\section{Discussion}

The current study examined the effect of adolescent and adult alcohol exposure on myelin in the frontal lobes of male rats. Similar to human studies, we found negative correlations between adolescent alcohol drinking and white matter. We also provide empirical evidence that alcohol reduces myelin density in adolescent rats and causes enduring white matter deficits in the $\mathrm{mPFC}$. Alcohol treatment-adolescent binge drinking or adult dependence-reduced the size of the $\mathrm{CC}_{\mathrm{FM}}$ and this neuropathology was predictive of higher levels of relapse-like drinking. Adolescent drinking predicted poor performance on an mPFCdependent task. Structural changes in white matter and degraded myelin health persisted well into abstinence in adulthood, suggesting that adolescent binge drinking produces irreversible changes in prefrontal circuitry.

The effect of alcohol on $\mathrm{CC}_{\mathrm{FM}}$ axons may have broad implications for adolescent and adult mental health outcomes. This anterior fiber bundle connects the mPFC to the lateral prefrontal cortex and striatum, and is implicated in depression, multiple sclerosis, Tourette's syndrome, and chronic schizophrenia (Cader et al., 2006; Friedman et al., 2008; Jackson et al., 2011; Tadayonnejad et al., 2014). The structures interconnected by the $\mathrm{CC}_{\mathrm{FM}}$ are also implicated in addiction (Everitt and Robbins, 2005; Volkow et al., 2005) and our current data suggest impaired connectivity may influence drinking risk in adulthood. Reduced $\mathrm{CC}_{\mathrm{FM}}$ size predicted augmented drinking during relapse tests, but did not predict increased baseline drinking behavior. Importantly, relapse-like drinking behavior was normalized for each animal to his own baseline. This suggests that the link between $\mathrm{CC}_{\mathrm{FM}}$ structure and relapse is not simply reflecting the effect of alcohol dose on $\mathrm{CC}_{\mathrm{FM}}$ axons. Instead, these axons may help control the magnitude of increase in alcohol intake, or "over-doing it," after experiencing short periods of abstinence from drinking.

Adolescent alcohol drinking and adult alcohol dependence produced changes of similar magnitude in the $\mathrm{CC}_{\mathrm{FM}}$. This is remarkable considering the substantial difference in the duration and dose of alcohol exposure between the two treatment groups. Binge rats consumed alcohol voluntarily, reaching $0.08 \mathrm{~g} / \mathrm{dl}$ BALs in only some of the drinking bouts over a 2 week adolescent drinking period that took place early in adolescence, $>5$ months before the brains were processed in adulthood. Conversely, dependence was induced in adulthood by 1 month of exposure to daily cycles of alcohol vapor-induced intoxication that maintained BALs between 0.15 and $0.20 \mathrm{~g} / \mathrm{dl}$ for $14 \mathrm{~h} / \mathrm{d}$ - an exposure that produces mild physical dependence (Richardson et al., 2008). The fact that the adolescent alcohol exposure duration and amount was much less than vapor exposure in adulthood suggests that the adolescent brain has heightened sensitivity to alcohol and the effects are enduring. The data support the hypothesis that the dynamic changes occurring in the developing prefrontal cortices during adolescence (Casey et al., 2008) increase susceptibility to potentially toxic external stimuli such as alcohol (Crews et al., 2007). The fact that dependence induction did not further reduce $\mathrm{CC}_{\mathrm{FM}}$ size in the binge group suggests a ceiling effect of alcohol on degradation of this axonal bundle.

The lack of group changes in $\mathrm{CC}_{\mathrm{Genu}}$ structure suggests that higher doses and a more prolonged exposure to alcohol, perhaps in combination with vitamin B1 deficiency, may be required to significantly impair white matter structure, as previously suggested (He et al., 2007; Pfefferbaum et al., 2008). This notion is supported by the significant inverse correlation between adolescent alcohol consumption and $\mathrm{CC}_{\mathrm{Genu}}$ size observed in this study. It will be important in future studies to determine how prefrontal myelin is damaged by alcohol using other models of alcohol use disorders (Simms et al., 2008; Crabbe et al., 2009) and to extend these findings to females.

Finally, to assay functional integrity of the mPFC, we tested rats for spontaneous alternation on the T-maze using a 70 s delay to increase working memory demand (Delatour and GisquetVerrier, 1996; Lalonde, 2002). Higher binge drinking levels during adolescence predicted poorer performance on the T-maze task in adulthood. This relationship was not evident in control rats, suggesting that alcohol consumption produces enduring functional changes in mPFC circuitry. Nevertheless, without a significant main effect, we cannot exclude the possibility that the correlation between alcohol and performance may reflect a relationship that is not causal in nature. The lack of a significant main effect could be due to variability in intake, as well as limitations in assaying a subtle cognitive impairment. In future studies, treatment differences in performance might be detected after increasing the retention interval, i.e., a larger delay between sample and choice phases (Deacon and Rawlins, 2006).

In conclusion, the present study provides causal evidence for alcohol-induced reductions in myelin in prefrontal circuits. To the best of our knowledge, this is the first study to show that adolescent voluntary binge drinking reduces the density of myelinated axons in the MPFC and has long-lasting effects on prefrontal white matter. Future work exploring the mechanisms by which alcohol damages prefrontal myelin may lead to new therapeutic strategies for the treatment of alcohol use disorders. 


\section{References}

Barnea-Goraly N, Menon V, Eckert M, Tamm L, Bammer R, Karchemskiy A, Dant CC, Reiss AL (2005) White matter development during childhood and adolescence: a cross-sectional diffusion tensor imaging study. Cereb Cortex 15:1848-1854. CrossRef Medline

Becker HC (2013) Animal models of excessive alcohol consumption in rodents. Curr Top Behav Neurosci 13:355-377. CrossRef Medline

Blakemore SJ, Choudhury S (2006) Development of the adolescent brain: implications for executive function and social cognition. J Child Psychol Psychiatry 47:296-312. CrossRef Medline

Broadwater M, Varlinskaya EI, Spear LP (2013) Effects of voluntary access to sweetened ethanol during adolescence on intake in adulthood. Alcohol Clin Exp Res 37:1048-1055. CrossRef Medline

Cader S, Cifelli A, Abu-Omar Y, Palace J, Matthews PM (2006) Reduced brain functional reserve and altered functional connectivity in patients with multiple sclerosis. Brain 129:527-537. CrossRef Medline

Casey BJ, Jones RM, Hare TA (2008) The adolescent brain. Ann N Y Acad Sci 1124:111-126. CrossRef Medline

Crabbe JC, Metten P, Rhodes JS, Yu CH, Brown LL, Phillips TJ, Finn DA (2009) A line of mice selected for high blood ethanol concentrations shows drinking in the dark to intoxication. Biol Psychiatry 65:662-670. CrossRef Medline

Crews F, He J, Hodge C (2007) Adolescent cortical development: a critical period of vulnerability for addiction. Pharmacol Biochem Behav 86:189199. CrossRef Medline

Crone EA, Bullens L, van der Plas EA, Kijkuit EJ, Zelazo PD (2008) Developmental changes and individual differences in risk and perspective taking in adolescence. Dev Psychopathol 20:1213-1229. CrossRef Medline

Deacon RM, Rawlins JN (2006) T-maze alternation in the rodent. Nat Protoc 1:7-12. CrossRef Medline

Delatour B, Gisquet-Verrier P (1996) Prelimbic cortex specific lesions disrupt delayed-variable response tasks in the rat. Behav Neurosci 110:12821298. CrossRef Medline

Everitt BJ, Robbins TW (2005) Neural systems of reinforcement for drug addiction: from actions to habits to compulsion. Nat Neurosci 8:14811489. CrossRef Medline

Friedman JI, Tang C, Carpenter D, Buchsbaum M, Schmeidler J, Flanagan L, Golembo S, Kanellopoulou I, Ng J, Hof PR, Harvey PD, Tsopelas ND, Stewart D, Davis KL (2008) Diffusion tensor imaging findings in firstepisode and chronic schizophrenia patients. Am J Psychiatry 165:10241032. CrossRef Medline

Gilpin NW, Karanikas CA, Richardson HN (2012) Adolescent binge drinking leads to changes in alcohol drinking, anxiety, and amygdalar corticotropin releasing factor cells in adulthood in male rats. PLoS One 7:e31466. CrossRef Medline

Grant BF, Dawson DA (1998) Age of onset of drug use and its association with DSM-IV drug abuse and dependence: results from the National Longitudinal Alcohol Epidemiologic Survey. J Subst Abuse 10:163-173. CrossRef Medline

He X, Sullivan EV, Stankovic RK, Harper CG, Pfefferbaum A (2007) Interaction of thiamine deficiency and voluntary alcohol consumption disrupts rat corpus callosum ultrastructure. Neuropsychopharmacology 32: 2207-2216. CrossRef Medline

Jackson SR, Parkinson A, Jung J, Ryan SE, Morgan PS, Hollis C, Jackson GM (2011) Compensatory neural reorganization in Tourette syndrome. Curr Biol 21:580-585. CrossRef Medline

Karanikas CA, Lu YL, Richardson HN (2013) Adolescent drinking targets corticotropin-releasing factor peptide-labeled cells in the central amygdala of male and female rats. Neuroscience 249:98-105. CrossRef Medline

Konrad A, Vucurevic G, Lorscheider M, Bernow N, Thümmel M, Chai C, Pfeifer P, Stoeter P, Scheurich A, Fehr C (2012) Broad disruption of brain white matter microstructure and relationship with neuropsycho- logical performance in male patients with severe alcohol dependence. Alcohol Alcohol 47:118-126. CrossRef Medline

Lalonde R (2002) The neurobiological basis of spontaneous alternation. Neurosci Biobehav Rev 26:91-104. CrossRef Medline

Li S, Stys PK (2000) Mechanisms of ionotropic glutamate receptormediated excitotoxicity in isolated spinal cord white matter. J Neurosci 20:1190-1198. Medline

Matsuo A, Lee GC, Terai K, Takami K, Hickey WF, McGeer EG, McGeer PL (1997) Unmasking of an unusual myelin basic protein epitope during the process of myelin degeneration in humans: a potential mechanism for the generation of autoantigens. Am J Pathol 150:1253-1266. Medline

McQueeny T, Schweinsburg BC, Schweinsburg AD, Jacobus J, Bava S, Frank LR, Tapert SF (2009) Altered white matter integrity in adolescent binge drinkers. Alcohol Clin Exp Res 33:1278-1285. CrossRef Medline

Paxinos G, Watson C (1998) The rat brain: in stereotaxic coordinates, Ed 4. San Diego: Academic.

Pfefferbaum A, Adalsteinsson E, Sullivan EV (2006) Dysmorphology and microstructural degradation of the corpus callosum: interaction of age and alcoholism. Neurobiol Aging 27:994-1009. CrossRef Medline

Pfefferbaum A, Zahr NM, Mayer D, Vinco S, Orduna J, Rohlfing T, Sullivan EV (2008) Ventricular expansion in wild-type Wistar rats after alcohol exposure by vapor chamber. Alcohol Clin Exp Res 32:1459-1467. CrossRef Medline

Rasband WS (1997) ImageJ. U.S. National Institutes of Health. Bethesda, Maryland.

RCoreTeam (2013) R: a language and environment for statistical computing. Vienna. Available at: http://www.R-project.org.

Richardson HN, Lee SY, O’Dell LE, Koob GF, Rivier CL (2008) Alcohol selfadministration acutely stimulates the hypothalamic-pituitary-adrenal axis, but alcohol dependence leads to a dampened neuroendocrine state. Eur J Neurosci 28:1641-1653. CrossRef Medline

Romer D (2010) Adolescent risk taking, impulsivity, and brain development: implications for prevention. Dev Psychobiol 52:263-276. CrossRef Medline

Schmued L, Bowyer J, Cozart M, Heard D, Binienda Z, Paule M (2008) Introducing Black-Gold II, a highly soluble gold phosphate complex with several unique advantages for the histochemical localization of myelin. Brain Res 1229:210-217. CrossRef Medline

Simms JA, Steensland P, Medina B, Abernathy KE, Chandler LJ, Wise R, Bartlett SE (2008) Intermittent access to $20 \%$ ethanol induces high ethanol consumption in Long-Evans and Wistar rats. Alcohol Clin Exp Res 32:1816-1823. CrossRef Medline

Stephens DN, Duka T (2008) Cognitive and emotional consequences of binge drinking: role of amygdala and prefrontal cortex. Philos Trans R Soc Lond, B, Biol Sci 363:3169-3179. CrossRef Medline

Tadayonnejad R, Yang S, Kumar A, Ajilore O (2014) Multimodal brain connectivity analysis in unmedicated late-life depression. PLoS One 9:e96033. CrossRef Medline

Taren AA, Venkatraman V, Huettel SA (2011) A parallel functional topography between medial and lateral prefrontal cortex: evidence and implications for cognitive control. J Neurosci 31:5026-5031. CrossRef Medline

Vendruscolo LF, Roberts AJ (2014) Operant alcohol self-administration in dependent rats: focus on the vapor model. Alcohol 48:277-286. CrossRef Medline

Volkow ND, Wang GJ, Ma Y, Fowler JS, Wong C, Ding YS, Hitzemann R, Swanson JM, Kalivas P (2005) Activation of orbital and medial prefrontal cortex by methylphenidate in cocaine-addicted subjects but not in controls: relevance to addiction. J Neurosci 25:3932-3939. CrossRef Medline

Walker BM, Walker JL, Ehlers CL (2008) Dissociable effects of ethanol consumption during the light and dark phase in adolescent and adult Wistar rats. Alcohol 42:83-89. CrossRef Medline 